\title{
Preferences of judges for product development using Naala (Tape) weaving techniques
}

\author{
KAMALPREET KAUR AND KANWALJIT KAUR BRAR
}

Received: 14.02.2017; Revised: 08.04.2017; Accepted: 25.04.2017

See end of the paper for authors' affiliations

\section{KAMALPREET KAUR}

Department of Apparel and Textile

Science, College of Home Science,

Punjab Agricultural University,

LUDHIANA (PUNJAB) INDIA
ABSTRACT : Traditional Naala making craft of Punjab is on the verge of varnishing. Thus, an effort was made to study opinion of clothing and textile experts for diversification of the craft. Total twenty eight designs comprising of four designs for each of seven most preferred products by college -girls were sketched. Product-wise preferences with respect to designs, motifs, yarns, colours were taken from a panel of randomly selected ten judges comprising of faculty and postgraduate students from Department of Apparel and Textile Science. Among the four designs of shrugs (A), first rank was given to $\mathrm{A}_{3}$ (mean score 2.8). Design $\mathrm{L}_{1}$ comb (Kanghi) for cap and design $\mathrm{L}_{2}$ (plain) for bolster got first rank with equal mean score 7.56. Design $\mathrm{L}_{3}$ lozenges (Burfi) for cushion cover, design $\mathrm{L}_{4}$ square (Dabbiyan) for skirt and design $\mathrm{L}_{5}$ holes (Moriyaan) for shrug obtained first rank with mean score 7.11 and 5.3, respectively. First rank was given to design $\mathrm{F}_{6}$ of a bag with mean score 6.3 and design $\mathrm{F}_{1}$ for footwear with mean score 6.5. First rank was given to yarn $\mathrm{Y}_{2}$ for shrug with mean score 11.2, yarn $\mathrm{Y}_{3}$ for bag (mean score 10.4). Out of twenty eight developed designs of products, seven most preferred designs of products were prepared through naala making technique.

KEY WORDS: Product designs, Naala (tape), Motifs, Yarns

- HOW TO CITE THIS PAPER : Kaur, Kamalpreet and Brar, Kanwaljit Kaur (2017). Preferences of judges for product development using Naala ( Tape) weaving techniques. Asian J. Home Sci., 12 (1) : 135142, DOI: 10.15740/HAS/AJHS/12.1/135-142. 